\title{
Urodynamic findings in chronic retention of urine and their relevance to results of surgery
}

\author{
PAUL H ABRAMS， M DUNN， N GEORGE
}

patients were all thought to have chronic retention of urine secondary to outflow-tract obstruction. They were able to micturate but could not empty their bladders. In each case the residual urine was over $300 \mathrm{ml}$. This was chosen as the minimum volume at which the bladder becomes palpable suprapubically: this is a widely accepted, though unpublished, definition of chronic retention.

A detailed history was taken from each patient and a physical examination performed. Intravenous pyelograms had been obtained in 38 patients and we reviewed these, noting the presence or absence of dilatation of the upper urinary tract. We then carried out the urodynamic studies-namely, inflow cystometry and pressure analysis of micturition. At the beginning of the examination the patient tried to empty his bladder in private, the urine flow rate being measured. He was then catheterised, a fine epidural catheter being passed via the urethra with an $8 \mathrm{~F}$-gauge Harris catheter. The bladder was emptied and the residual urine measured. The bladder was then filled through the $8 \mathrm{~F}$ catheter with saline $($ at $37 \mathrm{C}$ ) at the rate of $1 \mathrm{ml} / \mathrm{s}$. The rectal and bladder pressures were measured throughout filling and subsequent voiding. The rectal pressure, taken as an approximation of intra-abdominal pressure, was measured via a fluid-filled manometer whose tubing was protected at its end by a finger cot. The bladder pressure was measured via the epidural catheter. Both pressures were measured with a strain gauge transducer (Elema Schonander 431) and recorded on a multichannel recorder (Mictiograph 81). The bladder was filled until the patient thought that it was full. The filling catheter was then removed, leaving the pressure-measuring (epidural) catheter in situ. The patient then voided in private. The residual urine was calculated on the basis of the volume voided and the time of filling at a known rate.

The normal rise in detrusor pressure from zero volume to full capacity is under $15 \mathrm{~cm} \mathrm{H}_{2} \mathrm{O}$. In this study all patients with pressure rises of less than $25 \mathrm{~cm} \mathrm{H}_{2} \mathrm{O}$ were classified as having a low filling pressure; those with pressure rises above $25 \mathrm{~cm} \mathrm{H}_{2} \mathrm{O}$ were classified as having high-pressure filling. From the pressure-flow analysis of micturition all patients with a urethral resistance factor (given by peak flow pressure $/(\text { peak flow })^{2}$ ) above 0.6 were considered to have obstruction.

Twenty-five patients subsequently underwent outflow-tract surgery and were assessed as above at least six months after operation. nosis of patients with chronic retention of urine have been little discussed, although reports have detailed the surgical management of persistent problems. Several clinical observations are often described, however, one such being the abdominal findings. Mitchell: described how some patients with chronic retention had soft, flabby bladders, which were difficult to define; others had tense, firm bladders, whose edges were readily defined. $\mathrm{He}$ suggested that these two types of chronic retention were associated with low and high bladder pressures respectively. To date there have been no reports of evaluation before and after surgery of patients with chronic retention of urine. We therefore carried out such an investigation.

\section{Patients and methods}

A consecutive series of 55 male patients aged 18-77 with chronic retention of urine was investigated during 1975-8. Seven patients had abnormal neurological signs due to disseminated sclerosis, fractured spine, prolapsed intervertebral disc, and spinal cord tumour. These patients were excluded from the study. The remaining 48

Department of Urology, Southmead General Hospital, Bristol BS10 5NB

PAUL H ABRAMS, MD, FRCS, surgical registrar

M DUNN, CHM, FRCS, senior registrar in urology

N GEORGE, FRCS, registrar in urology

\section{Results}

On cystometry 27 patients showed normal-pressure bladder filling - that is, the pressure rose less than $25 \mathrm{~cm} \mathrm{H}_{2} \mathrm{O}$. The remaining 21 patients showed pressure increases of over $25 \mathrm{~cm} \mathrm{H}_{2} \mathrm{O}$ and were

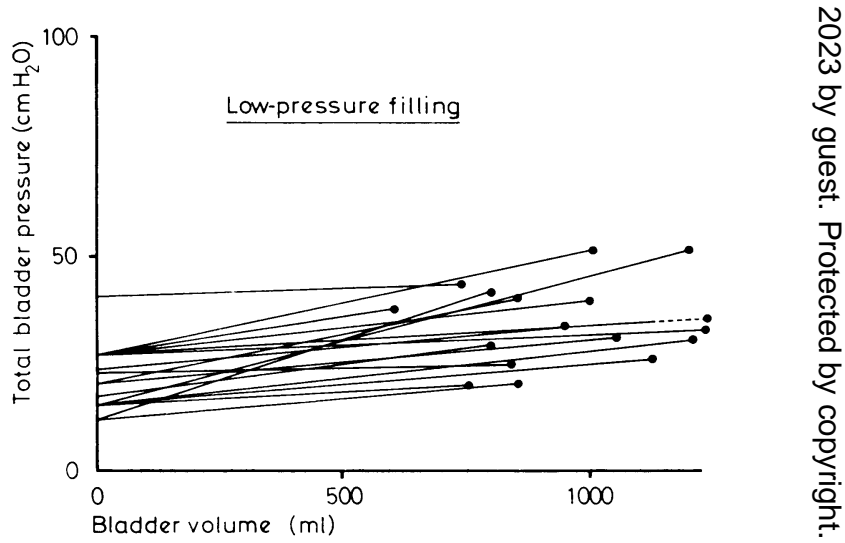

FIG 1-Diagrammatic cystometrograms from first 17 patients with low-pressure bladder filling. 
therefore classified as having high-pressure bladder filling. No patient in this group showed phasic contractions characteristic of bladder instability. Fig 1 shows the cystometric findings in the first 17 patients with low-pressure filling, and fig 2 the findings in the first 10 patients with high-pressure filling. In all the patients with lowand high-pressure filling the mean pressure increases were respectively $11 \mathrm{~cm} \mathrm{H}_{2} \mathrm{O}$ (range 0-25) and $82 \mathrm{~cm} \mathrm{H}_{2} \mathrm{O}$ (40-148); mean bladder capacities $960 \mathrm{ml}$ (470-3000) and $825 \mathrm{ml}$ (380-3500); and mean residual urine volumes $755 \mathrm{ml}(320-2550)$ and $715 \mathrm{ml}(310-3200)$. Pressure-flow analysis of micturition showed that all patients had outlet obstruction.

Fifteen patients complained of enuresis of recent onset. Table I shows the statistical association between enuresis and high-pressure bladder filling. The two groups also tended to have different symptom complexes. The low-pressure group tended to complain of hesitancy, slow stream, and a feeling of incomplete emptying, while the highpressure group also complained of urgency.

The data from physical examination is incomplete as this series was partly retrospective. We gained the impression, however, that patients with low-pressure filling had bladders that were difficult to define on abdominal palpation, whereas patients with high-pressure filling had tense, readily palpated bladders. No difference in the rectal findings of the two groups was noted.

Review of the excretion urograms showed upper-tract dilatation in 17 patients. This was bilateral in 12 patients and unilateral in five. The distribution of these patients (table II) shows the statistical association between upper-tract dilatation and high-pressure bladder filling. In the four patients with upper-tract dilatation but lowpressure filling the dilatation was confined to one side (to the left in three and the right in one).

The urodynamic studies carried out after operation on 22 patients showed that in all cases the obstruction had been relieved, since micturition pressures were lower and urine flow rates higher. Results of surgery (table III) were assessed according to the postoperative residual urine and the symptomatic response of the patient. Patients who had high-pressure bladder filling before operation showed a more

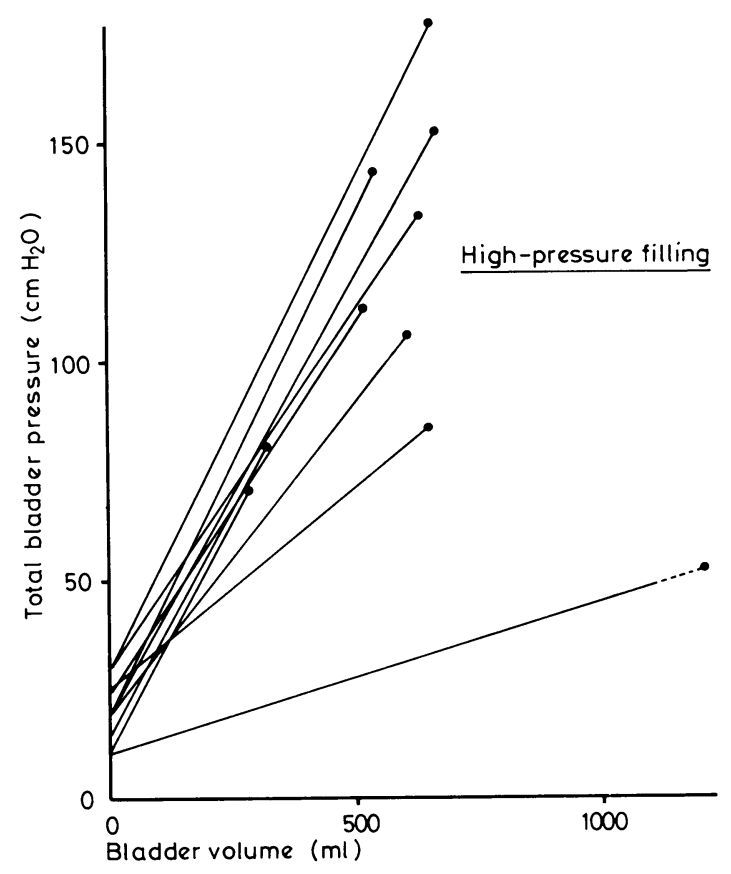

FIG 2-Diagrammatic cystometrograms from the first 10 patients with high-pressure bladder filling.

TABLE I-Relation between enuresis and cystometric findings in patients with chronic retention of urine

\begin{tabular}{ll|c|c}
\hline & $\begin{array}{c}\text { High-pressure filling } \\
(\mathrm{n}=21)\end{array}$ & $\begin{array}{c}\text { Normal-pressure filling } \\
(\mathrm{n}=27)\end{array}$ \\
\hline Enuresis $(\mathrm{n}=15)$ & $\ldots$ & 13 & 2 \\
No enuresis $(\mathrm{n}=33)$ & $\cdots$ & 8 & 25 \\
\hline
\end{tabular}

$\chi^{2}=16 \cdot 7, \mathrm{DF}=1, \mathrm{P}<0 \cdot 01$
TABLE II-Relation between upper-tract dilatation seen on excretion urography and cystometric findings in patients with chronic retention of urine

\begin{tabular}{ll|c|c}
\hline & $\begin{array}{c}\text { High-pressure } \\
\text { filling }(\mathrm{n}=18)\end{array}$ & $\begin{array}{c}\text { Normal-pressure } \\
\text { filling }(\mathrm{n}=20)\end{array}$ \\
\cline { 1 - 3 } Upper-tract dilatation $(\mathrm{n}=17)$ & $\ldots$ & 13 & 4 \\
No upper-tract dilatation $(\mathrm{n}=21)$ & $\cdots$ & 5 & 16 \\
\hline
\end{tabular}

$\varkappa^{2}=10 \cdot 2, \mathrm{DF}=1, \mathrm{P}<0 \cdot 01$

TABLE III-Relation between results of surgery and the preoperative cystometric findings in 22 patients with chronic retention of urine

\begin{tabular}{c|c|c}
\hline $\begin{array}{c}\text { Results of } \\
\text { surgery }\end{array}$ & $\begin{array}{c}\text { High-pressure filling } \\
(\mathrm{n}=10)\end{array}$ & $\begin{array}{c}\text { Normal-pressure filling } \\
(\mathrm{n}=12)\end{array}$ \\
\hline $\begin{array}{c}\text { Good }(\mathrm{n}=13) \ldots \ldots \\
\text { Unsatisfactory }(\mathrm{n}=9) \cdots\end{array}$ & 9 & 4 \\
\hline$\chi^{2}=7 \cdot 28, \mathrm{DF}=1, \mathrm{P}<0.01$. & 1 & 8 \\
\hline
\end{tabular}

satisfactory response to surgery, the cystometrograms in all these patients showing low-pressure filling after the prostatectomy. No patient with low-pressure filling developed high-pressure filling after operation. After prostatectomy the patients with high-pressure filling achieved good bladder emptying by normal detrusor contraction. The poor results in the patients with low-pressure filling were due to inadequate detrusor contraction, and voiding was accomplished by abdominal straining.

\section{Discussion}

From the results of our urodynamic studies we were able to divide patients with chronic retention of urine into two main groups and so could accurately predict the outcome of prostatic surgery. Patients with high bladder pressures tend to do well after adequate prostatic surgery, but results in those with low bladder pressures are less satisfactory. Patients with persisting symptoms should be reassessed urodynamically, since the symptoms might be due to detrusor failure rather than persisting obstruction and further prostatic surgery might lead to incontinence.

This urodynamic identification of two separate groups among patients with chronic retention confirms the clinical impressions of Mitchell.2 The pathogenesis of these groups, however, remains obscure. Patients with low-pressure filling have an obstruction and inadequate detrusor contraction during voiding. The inadequate voiding contraction becomes more obvious after operation. Patients who initially have highpressure filling lose the large pressure rise on filling after operation.

Much has been written about bladder instability recently. Waves of detrusor contraction occur during bladder filling (unstable bladders) in half the patients with prostatism and usually disappear after relief of obstruction. ${ }^{3}$ Possibly the cystometric findings in the high-pressure group represent a form of instability, although no phasic activity was seen during filling in our patients. The reversal after operation suggests a neuromuscular abnormality rather than any mechanical abnormality of the wall, which would be unlikely to disappear after operation.

Normally enuresis means bladder voiding during sleep, implying a detrusor contraction. As used here it means that the patients woke up wet; it is not meant to imply that a voiding contraction occurred. More probably the leakage occurs during sleep when the bladder pressure exceeds the sphincter pressure. Although the high-pressure group complained of urgency, the first desire to void and then urgency did not occur until the filling pressure was extremely high, often above $80 \mathrm{~cm} \mathrm{H}_{2} \mathrm{O}$. A detrusor pressure of $80 \mathrm{~cm} \mathrm{H}_{2} \mathrm{O}$ in a normal person is associated with detrusor contraction and a powerful desire to void. The patients with high bladder pressure seemed to have decreased sensation, which probably explains their night wetting.

Upper-tract dilatation may be due to either stasis or passive 
vesicoureteric reflux. As the abnormality was visible on the excretion urogram, stasis is the probable explanation. In patients with true vesicoureteric reflux this is normally only seen on micturating cystourethrography. Unfortunately none of our patients underwent this procedure, which would probably have elucidated the cause. Evidence from animal experiments shows maximum ureteric pressures of about $60-80 \mathrm{~cm} \mathrm{H}_{2} \mathrm{O}$ at the peak of a peristaltic wave. ${ }^{+}$If such levels are attained in the human ureter high-pressure filling would probably lead to obstruction at the vesicoureteric junction.

The postoperative results in this study show the range of responses to surgery of patients with chronic retention. Patients with low-pressure filling and inadequate detrusor contraction during voiding respond least well. After prostatic surgery they still complain of a slow stream, hesitancy, and a feeling of incomplete emptying. When closely questioned they also often admit to having to strain to void. Their postoperative symptoms, however, suggest residual obstruction. If urodynamic investigations are not used to investigate postprostatectomy symptoms such as these persistent obstruction may be diagnosed. In a previous study several such patients were seen. Some had a second operation, which invariably failed to help them and in five cases led to the development of stress incontinence, presumably due to impairment of the continence mechanisms at and immediately proximal to the external sphincter.

Several operations that aim to improve bladder emptying by decreasing bladder volume-namely, partial cystectomy, vesicoplication, and cystoplasty-have been described '- ' but have been little used in our area. Vesicoplication yields disappointing results and is now rarely performed. Urodynamic studies after vesicoplication in six patients showed a persistently high residual urine and little change in the symptoms.

This study has served to define the types of chronic retention found in men and show that urodynamic investigations predict which patients are likely to benefit from prostatectomy. Postoperative urodynamic studies indicate whether the obstruction has been relieved or still persists; they may also explain any persistent postoperative symptoms the patient might have and indicate whether further surgical intervention is warranted.

\section{References}

${ }^{1}$ Abrams, P H, British Fournal of Surgery, 1976, 63, 655.

2 Mitchell, J P, The Principles of Transurethral Resection and Haemostasis, p 173. Bristol, J Wright and Sons, 1972.

${ }^{3}$ Abrams, $\mathrm{P} \mathrm{H}$, Urologia Internationalis, in press.

* Boyarsky, S, and Labay, P, Ureter Dynamics, p 340. Baltimore, Williams and Wilkins, 1972.

Swinney, J, British Fournal of Urology, 1958, 30, 423.

${ }^{6}$ Hamilton-Stewart, H, British fournal of Urology, 1966, 38, 685.

7 Binard, J E C, and Zoedler, D, International Surgery, 1968, 50, 502.

(Accepted 6 September 1978)

\title{
Ethanol-induced increase in drug acetylation in man and isolated rat liver cells
}

\author{
HARALD OLSEN， JØRG MØRLAND
}

British Medical fournal, 1978, 2, 1260-1262

\section{Summary and conclusions}

Sixteen healthy volunteers took part in a cross-over study examining the effect of ethanol on the rate of sulphadimidine acetylation (blood ethanol concentration about $1 \mathrm{~g} / 1)$. In both rapid and slow acetylators the apparent half life of the drug decreased by about $20 \%$ after ethanol (mean reduction 39 SE $8 \mathrm{~min}$ ) and the amount of drug acetylated, measured in blood and urine, increased. In three slow acetylators the rate of acetylation in blood increased so noticeably after ethanol that they would otherwise have been classified as rapid acetylators. Suspensions of isolated rat liver cells showed an increase of about $30 \%$ in the rate of sulphadimidine acetylation after the addition of ethanol ( $2 \mathrm{~g} / 1)$.

Patients' usual alcohol consumption should be taken into account in determining their acetylator status. Department of Clinical Pharmacology, University Hospital,
Troms $\varnothing$ N-9012, Norway

HARALD OLSEN, MD, clinical pharmacologist

Institute of Medical Biology, University of Troms $\varnothing$, N-9001 Troms $\phi$, Norway

JØRG MØRLAND, MD, professor of pharmacology
Introduction

The acute interaction between ethanol and drugs usually leads to a decreased rate of drug metabolism. Both oxidation and conjugation of drugs with glucuronic acid, for example, may be inhibited by ethanol. ${ }^{1-s}$ Theoretically, however, ethanol could have the opposite effect on drug acetylation and enhance the speed of this conjugation reaction: ethanol is metabolised to yield acetate ${ }^{910}$ and may increase the concentration of acetyl coenzyme A (CoA), ${ }^{11}$ the acetate donor in the $N$-acetyltransferase reaction leading to acetylation of drugs. ${ }^{12}$ If a low concentration of acetyl CoA is rate-limiting in this reaction ethanol metabolism may increase the velocity by enhancing the formation of acetyl CoA. We decided to test this hypothesis. The activity of $N$ acetyltransferase, which catalyses the transfer of acetyl groups to drugs such as hydrallazine, isoniazid, procainamide, and certain sulphonamides, is under genetic polymorphic control, and people may be classified as slow or rapid acetylators. ${ }^{13}$ Sulphadimidine is regarded as a model substance for acetylation, and we therefore used it in our studies.

\section{Materials and methods \\ IN-VIVO STUDIES ON MAN}

Sixteen healthy drug-free volunteers ( 6 women, 10 men) aged 18-36 years took part in a cross-over study. They were fasted overnight and at $8 \mathrm{am}$ received sulphadimidine by mouth $(10 \mathrm{mg} / \mathrm{kg})$. Two hours later they had a light breakfast, normal meals being allowed thereafter. Half the subjects received no further treatment, while the others had ethanol $\left(20^{\circ}{ }_{0} \mathrm{v} / \mathrm{v}\right.$ in fruit juice, $\left.0.73 \mathrm{~g} / \mathrm{kg}\right)$ two hours after taking the drug followed by hourly drinks of $0 \cdot 11 \mathrm{~g} / \mathrm{kg}$ until 10 hours after the 